\title{
Vaccination Hesitancy in Health Care Providers: The Example for the General Population in the Time of a Pandemic
}

\author{
Adriana Gaspar da Rocha ${ }^{a, b}$ Bárbara Santa-Rosa ${ }^{b, c}$ Duarte Nuno Vieira ${ }^{b}$ \\ Margarida Silvestre ${ }^{b, d}$ \\ a Public Health Unit, ACES Baixo Mondego, Coimbra, Portugal; b Institute of Bioethics, Faculty of Medicine, University \\ of Coimbra, Coimbra, Portugal; ' National Institute of Legal Medicine and Forensic Sciences, Coimbra, Portugal; \\ ${ }^{\mathrm{d}}$ Reproductive Medicine Department, Coimbra Hospital and University Centre, Coimbra, Portugal
}

\section{Keywords}

COVID-19 $\cdot$ Health ethics $\cdot$ Vaccination

\section{Hesitação vacinal em profissionais de saúde: o exemplo para a população em tempo de pandemia}

\section{Palavras Chave}

COVID-19 · Ética da Saúde · Vacinação
Coronavirus disease 2019 (COVID-19) is a contagious infection caused by severe acute respiratory syndrome coronavirus 2 (SARS-CoV-2) from the coronavirus family. The disease affected over 113 million people in 1 year and resulted in more than 2.5 million deaths [1]. Vaccines were developed during 2020, and the first inoculations were performed in December.

Vaccination is a proven tool for controlling and eliminating life-threatening infectious diseases and is one of the most cost-effective health investments. Universal vaccination programs promote equity, provide equal opportunities, and prevent disease, regardless of ethnicity, reli- gion, gender, income, or ideology. Vaccination is an indisputable human right [2].

In 2015, the Strategic Advisory Group of Experts (SAGE), the working group on Vaccine Hesitancy, indicated that "vaccine hesitancy refers to delay in acceptance or refusal of vaccination despite availability of vaccination services. Vaccine hesitancy is complex and context specific, varying across time, place, and vaccines. It is influenced by factors such as complacency, convenience and confidence" [3]. This " $3 \mathrm{Cs"} \mathrm{model} \mathrm{explains} \mathrm{the} \mathrm{com-}$ plexity of vaccine hesitancy and its determinants. Complacency occurs when the risks of diseases preventable by the vaccine are perceived as low and vaccination is not considered a necessary preventive action. Factors contributing to the convenience category include immediate availability of the vaccine, easy access (geographic, for example), being free of charge, and easy understanding of the information transmitted by vaccination professionals. Confidence relates to the effectiveness and safety of vaccines, the reliability and competence of health services and professionals, and health/vaccination policies [3].

Health care providers ( $\mathrm{HCP}$ ) are people whose job is to protect and improve the health of their communities [4]. Professional practice is regulated by a set of behaviour (c) 2021 The Author(s). Published by S. Karger AG, Basel on behalf of NOVA National School of Public Health

This is an Open Access article licensed under the Creative Commons Attribution-NonCommercial-4.0 International License (CC BY-NC) (http://www.karger.com/Services/OpenAccessLicense), applicable to the online version of the article only. Usage and distribution for commercial purposes requires written permission.
Correspondence to:

Adriana Gaspar da Rocha, adrianagaspardarocha@gmail.com 
rules and ethical norms that serve as guidance in the different aspects of human relationships. It is not expected that this professional group could voluntarily endanger the patients' health and life and, indirectly, the health service's community.

HCP are a particularly important group in vaccination plans and the rate of vaccinated professionals has globally been lower than desired, particularly with the influenza vaccine $[5,6]$. Over the past few years, the national vaccination plan for influenza has integrated HCP from the National Health Service in the first phase of administration of the vaccine, which is free of charge. In a study conducted by the Public Health Department of the Northern Regional Health Administration performed between 2009 and 2019, it was found that, in that region, vaccination coverage against seasonal influenza in HCP showed a decreasing trend, with a maximum value of $51.2 \%$ in $2009 / 10$ and a minimum of $28.5 \%$ in $2016 / 17$ [7]. In another study performed in 2013 at the Public Health Department of the Central Regional Health Administration, the author found that the more frequently pointed reasons for HCP to adhere to the influenza vaccine were "because the vaccine protects them," "because the vaccine protects patients," and "because it is a recommendation from national and international societies," while the main reasons for non-adherence to the vaccine were "having a low risk of getting flu," "having doubts about the vaccine's effectiveness," "fear of side effects," and "not considering that patients are at risk" [8].

In fact, influenza vaccination could offer valuable lessons for ensuring COVID-19 vaccine acceptance [9]. First, there are robust data regarding influenza vaccine acceptance by HCP; in fact, this is the model that has generated more evidence regarding vaccine adherence by HCP [10]. Furthermore, influenza and COVID-19 share a wide clinical spectrum and there is a strong possibility that, like in influenza, COVID-19 immunization may require periodic inoculation of the vaccine. However, there is a major limitation for this comparison: currently, the perception that COVID-19 has potentially more severe consequences increases the acceptance of the COVID-19 vaccine. Nevertheless, we should consider that, as time passes and the pandemic is controlled, the complacency of HCP tends to increase, leading to higher levels of vaccine hesitancy [11].

The number of cases of diseases preventable by vaccination among health professionals warns of the need to consider interventions that guarantee their protection, including vaccination and infection control and prevention measures. In 2018, there was an important outbreak

Vaccination Hesitancy in Time of a

Pandemic of measles in a hospital in Northern Portugal. In the epidemiological investigation carried out, it was possible to diagnose 85 cases in HCP, from a total of 96 [12]. In the previous year, there was a minor outbreak in the region of Lisbon and the Tagus Valley, with 20 confirmed cases, of which 12 were not vaccinated; of the 20 positives, 10 were HCP [13].

Vaccination of health teams can be economically beneficial and associated with health gains. Italian authors have shown the economic benefits outweigh the costs by a factor of 4.5 [14], and a study in Thailand showed that the financial cost of epidemiologically investigating an outbreak of influenza in three intensive care units was 10 times higher than vaccinating all HCP [15]. An increase in vaccination adherence by $\mathrm{HCP}$ from 4 to $67 \%$ may lead to significant reductions in the relative frequency of cases of influenza in the team, as well as in the proportion of cases that were acquired nosocomially in hospitalized patients, which may drop from 32 to $0 \%$ [16].

In a survey carried out in France with 2,000 participants, $28.8 \%$ of them responded that they would refuse to be vaccinated for COVID-19; this number increased to $32.3 \%$ in the group of HCP (40 out of 124 participants) [17]. In an Israeli study, it was found that HCP treating COVID-19 patients, as well as individuals who consider themselves at high risk of the disease, were more likely to self-report acceptance to vaccination. In contrast, parents, nurses, and health professionals not in direct contact with SARS-CoV-2-positive patients expressed high levels of vaccine hesitancy [18].

On December 3, 2020, the national vaccination plan against COVID-19 defined three phases of vaccination, and the HCP directly involved in providing care to patients were part of the first phase. On one hand, HCP have the recognized privilege of receiving the vaccine earlier than the rest of the population, on the other hand, it raises a moral and ethical responsibility to accept this benefit since they work with vulnerable people who depend on their good health [19].

When working in health care, the risk of contagion from infectious diseases increases, so vaccination is the most effective way to protect the professional individually, collectively the team with whom he or she works, and, especially, the patients who are being taken care of [20]. In recent months, SARS-CoV-2 outbreaks have been reported in hospital services and in residential homes for elderly people, frequently reaching a high number of professionals, often with fatal consequences for hospitalized patients. Furthermore, an outbreak in a health unit has another consequence: absenteeism. Man- 
agers are faced with the difficulty of replacing entire teams with other professionals, often without the same experience and competence in the area. It is recognized that many HCP share not only working time but also leisure time, such as meal breaks, making contact even closer and facilitating the spread of this and other diseases. Occupational health services play a key role in promoting a healthy work environment and preventing disease among professionals [20].

Evidence shows that misperceptions about vaccination are frequent, as well as divergences between knowledge and behaviour. Thus, knowledge of the risks and benefits of vaccination among HCP is not sufficient to guarantee good adherence. Communication messages need to be adapted to the needs of different groups of health professionals since the available evidence indicates that perceptions about the need, risks, and benefits of vaccination may vary in these groups. The inclusion of information on the importance of vaccination of HCP (selfprotection, responsibility to patients, preparation for pandemics), training (pre- and post-graduate) in the area of health can help to consolidate vaccination of HCP as an indisputable element to good professional practice [5, $21]$. Beyond this, an integrated policy leads to greater coordination and collaboration between occupational health programs and vaccination, and can promote a concerted approach to infection control in health institutions [21].

According to contemporary liberal ethics, the principles of self-determination and bodily integrity surpass any paternalistic appreciation of the best interest of a competent adult: your decision must prevail. However, sometimes there is a serious conflict between individual autonomy and public health. Public health is concerned with the health of communities and populations, in addition to the health of individuals, when considering the implementation and sustainability of global health programs, so it becomes evident that other ethical principles must guide the thinking and decision of HCP [22].

Public health is one of the cornerstones of an organized and modern society. Herd immunity produces social benefits, resulting in good health indicators and a reduction in public health expenditure, in addition to economic losses related to diseases; however, achieving population immunity through vaccination depends on the significant cooperation of individuals. Limited cooperation and consequently compromised immunity can have a highly damaging effect on the population health. The image of trusted HCP and scientific knowledge can play a crucial role in the adherence of individuals to vac- cination. Vaccination hesitancy in HCP can lead to low population adherence to the vaccine, particularly among the youngest or those without risk factors, threatening the desirable herd immunity [22-24].

Beauchamp and Childress [23] refer to three moral issues critical to the goal of public health: benefiting others, preventing and removing harms, and utility. Nonetheless, three considerations tend to limit public health activities: justice, respect for autonomy, and privacy. Giubilini [24] advocated that individual rights could be overcome by the interests of the community, always with proportionality, minimizing the infringement, and maximizing the intervention's benefit. Beauchamp and Childress [23] suggested that social justice and communitarian traditions should drive public health.

Medical practice should be guided by the values of respect for others, beneficence, autonomy, non-maleficence, justice, and truth; however, public health practice is often faced with opposing perspectives in the same reality [25]. Considering the high scientific and social value of vaccines, there should be considered a moral duty to protect the most valuable assets of the community and the individual: life and health. In a pandemic scenario, when public health is compromised and there is a safe, effective, and low-cost method of preventing disease or its more severe forms, health organizations and public health authorities have a responsibility to act. This is the key moment in which all HCP are called to set an example for society.

\section{Conflict of Interest Statement}

The authors have no conflicts of interest to declare.

\section{Funding Sources}

The authors have no funding sources to declare.

\section{Author Contributions}

All authors reviewed and approved the final version of the manuscript.
Port J Public Health 2021;39:74-77 DOI: $10.1159 / 000519488$
Gaspar da Rocha/Santa-Rosa/Vieira/ Silvestre 


\section{References}

1 European Centre for Disease Prevention and Control. COVID-19 situation dashboard [Internet]. Solna: ECDC; 2021. [cited $2021 \mathrm{Mar}$ 3]. Available from: https://qap.ecdc.europa. eu/public/extensions/COVID-19/COVID-19.html.

2 Brennan Ramirez LK, Baker EA, Metzler M. Promoting Health equity: a resource to help communities address social determinants of health. Atlanta: Department of Health and Human Services. Centers for Disease Control and Prevention; 2008.

3 MacDonald NE, Eskola J, Liang X, Chaudhuri M, Dubé E, Gellinet B, et al.; SAGE Working Group on Vaccine Hesitancy. Vaccine hesitancy: definition, scope and determinants. Vaccine. 2015 Aug;33(34):4161-4.

4 World Health Organization. The World Health Report 2006: working together for health [Internet]. Geneva: WHO; 2006 [cited 2020 Dec 13]. Available from: https://www. who.int/whr/2006/en/.

5 Haviari S, Bénet T, Saadatian-Elahi M, André $\mathrm{P}$, Loulergue P, Vanhems P. Vaccination of healthcare workers: a review. Hum Vaccin Immunother. 2015;11(11):2522-37.

6 Genovese C, Picerno IA, Trimarchi G, Cannavò G, Egitto G, Cosenza B, et al. Vaccination coverage in healthcare workers: a multicenter cross-sectional study in Italy. J Prev Med Hyg. 2019 Mar;60(1):E12-7.

7 Vidal-Castro J, Figueiredo LR, Almeida D, Figueiredo AL, Frutuoso A, Vieira M, et al. Cobertura vacinal da gripe sazonal em profissionais de saúde: 10 anos de avaliação na região Norte. In: Congresso Nacional de Médicos de Saúde Pública, Aveiro, 9 e 10 de Dezembro de 2019. Aveiro: Associação Nacional dos Médicos de Saúde Pública; 2019.

8 Marques LA. Adesão à vacina da gripe nos profissionais de saúde da ARSC, IP [Internet]. Coimbra: Escola Superior de Enfermagem de Coimbra; 2013. Dissertação de Mestrado em
Enfermagem Comunitária [cited 2020 Nov 20]. Available from https://www.rcaap.pt/detail.jsp?id=oai:repositorio.esenfc.pt: 4626 .

9 Gostin LO, Salmon DA. The dual epidemics of COVID-19 and influenza: vaccine acceptance, coverage, and mandates. JAMA. 2020 Jul;324(4):335-6.

10 Grochowska M, Ratajczak A, Zdunek G, Adamiec A, Waszkiewicz P, Feleszko W. A Comparison of the level of acceptance and hesitancy towards the influenza vaccine and the forthcoming COVID-19 vaccine in the medical community. Vaccines. 2021 May;9(5):475.

11 Kwok KO, Li KK, Wei WI, Tang A, Wong SY, Lee SS. Editor's choice: influenza vaccine uptake, COVID-19 vaccination intention and vaccine hesitancy among nurses: a survey. Int J Nurs Stud. 2021 Feb;114:103854.

12 Sá Machado R, Perez Duque M, Almeida S, Cruz I, Sottomayor A, Almeida I, et al. Measles outbreak in a tertiary level hospital, Porto, Portugal, 2018: challenges in the post-elimination era. Euro Surveill. 2018 May;23(20): e18-00224.

13 Augusto GF, Silva A, Pereira N, Fernandes T, Leça A, Valente P, et al. Report of simultaneous measles outbreaks in two different health regions in Portugal, February to May 2017: lessons learnt and upcoming challenges. Euro Surveill. 2019 Jan;24(3):e1800026.

14 Apisarnthanarak A, Puthavathana P, Kitphati R, Auewarakul P, Mundy LM. Outbreaks of influenza A among nonvaccinated healthcare workers: implications for resource-limited settings. Infect Control Hosp Epidemiol. 2008 Aug;29(8):777-80

15 Cella MT, Corona G, Tuccillo E, Franco G. [Assessment of efficacy and economic impact of an influenza vaccination campaign in the personnel of a health care setting]. Med Lav. 2005 Nov-Dec;96(6):483-9. Italian.
16 Salgado CD, Giannetta ET, Hayden FG, Farr BM. Preventing nosocomial influenza by improving the vaccine acceptance rate of clinicians. Infect Control Hosp Epidemiol. 2004 Nov;25(11):923-8.

17 Schwarzinger M, Watson V, Arwidson P, Alla F, Luchini S. COVID-19 vaccine hesitancy in a representative working-age population in France: a survey experiment based on vaccine characteristics. Lancet Public Health. 2021 Apr;6(4):e210-21.

18 Dror AA, Eisenbach N, Taiber S, Morozov NG, Mizrachi M, Zigron A, et al. Vaccine hesitancy: the next challenge in the fight against COVID-19. Eur J Epidemiol. 2020 Aug;35(8): 775-9.

19 Ministério da Saúde. Direção-Geral da Saúde. Plano de vacinação contra a COVID-19 [Internet]. Lisbon: DGS; 2020 [cited 2020 Dec 16]. Available from: https://covid19estamoson.gov.pt/wp-content/uploads/2020/12/plano-vacinacao-covid19.pdf.

20 Ministério da Saúde. Direção-Geral da Saúde. Programa Nacional de Saúde Ocupacional (PNSOC): extensão 2018/2020. Lisbon: DGS; 2018.

21 Organização Pan-Americana da Saúde Como implementar vacinação de profissionais da saúde contra infuenza sazonal. Brasilia: OPS; 2020.

22 Nuffield Council on Bioethics. Public health: ethical issues. London: Nuffield Council on Bioethics; 2007.

23 Beauchamp TL, Childress JF. Principles of Biomedical Ethics. 8th ed. New York: Oxford University Press; 2019.

24 Giubilini A. The ethics of vaccination. Cham: Palgrave MacMillan; 2019. https://doi. org/10.1007/978-3-030-02068-2.

25 Upshur RE. Principles for the justification of public health intervention. Can J Public Health. 2002 Mar-Apr;93(2):101-3.
Vaccination Hesitancy in Time of a Pandemic
Port J Public Health 2021;39:74-77

DOI: $10.1159 / 000519488$ 